\title{
OPEN
}

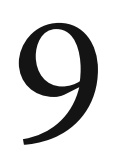

\section{Making Technology Assessment Accessible to New Players}

\author{
Pierre Delvenne, Benedikt Rosskamp, \\ Ciara Fitzgerald and Frédéric Adam
}

\begin{abstract}
Delvenne et al. present theoretical considerations about the pedagogy of technology assessment (TA) in general and the summer school format in particular, which was chosen as a platform for teaching TA in the PACITA project. The PACITA summer school programme was designed to encourage the uptake and use of TA rationale and methods by various types of professionals involved in science, technology or innovation policy. The recruitment strategies, the format of the presentations, and so on of the two summer schools are presented. The authors argue that as the 'responsible innovation' agenda gains traction among policy makers, societal actors and academics, education initiatives such as the TA summer school can have an important role to play in shaping understandings of this new form of governance.
\end{abstract}

Klüver, Lars, Rasmus Øjvind Nielsen, and Marie Louise Jørgensen, eds. Policy-Oriented Technology Assessment Across Europe: Expanding Capacities. Basingstoke: Palgrave Macmillan, 2016. DOI: 10.1057/9781137561725.0020. 
This chapter reports on the two PACITA summers schools, which were aimed at teaching TA as well as enhancing mutual-learning activities. The first summer school concentrated on 'Renewable Energy Systems' role and use of PTA' and it was held in Liège, Belgium, in June 2012. The second summer school addressed the topic of 'Ageing and Technology' and was held in Cork in June 2014. We describe the rationale and format of the summer school in order to present a comprehensive account of how it introduced TA, both its rational and its methods, to a new audience. We argue that as the responsible innovation agenda continues to gain traction among policy makers, societal actors and academics, education initiatives such as TA summer schools can have an important role to play in the future of the governance of science, technology and innovation.

\section{Background and rationale}

Training and learning activities in TA encompass a great variety of approaches, including embedding TA-like courses into engineering and natural scientific curricula or TA practitioners training. In the former case, the objective is to raise students' awareness of social and ethical dimensions relative to technology development and implementation. But in the latter case the objective is to exchange best practices and, by doing so, constituting a community of practitioners and even a scientific (inter)discipline that goes beyond the established community of TA practitioners. However, along these already existing activities, which are organized and implemented in a number of ways in European countries, the PACITA project stressed that in a context in which knowledge-based policy making is increasingly needed, very few TA training activities directly target policy makers. This creates two major difficulties. First, a broad set of policy makers and innovation actors from countries where TA institutions are already established, when they are aware of what TA is, might not be conscious that they could use already existing TA knowledge to address the policy-making issues that they are confronted with. Second, in countries where TA practices are not institutionalized as such, policy makers may fail to support the need to further establish such activities, more by lack of knowledge about TA rather than by lack of enthusiasm. This calls for a need to provide them with convincing evidence that TA knowledge is of valuable potential for their daily work. 
In what follows, we argue that the further development of training activities such as TA summer schools is a relevant tool for doing so.

In PACITA, the rationale of TA summer schools was to broadly consider potential users of TA knowledge, such as policy makers, civil society organizations, scientists, science communicators and journalists, as well as civil servants, and to sensitize them to the role and added value of TA to their working practices and organizations' objectives. In line with PACITA's aim to expand the TA landscape in European countries which do not count institutionalized TA bodies, summer schools explicitly (though not exclusively) targeted new players in such countries - for example, Belgium, Lithuania, Bulgaria, Portugal, Ireland, Hungary or the Czech Republic. Furthermore, the summer schools also engaged participants from countries with established TA institutions who do not always recognize their TA activities because they believe they do not appear as the main addressee of TA activities. Lastly, the summer schools offered an opportunity to open up and sensitize TA and knowledge-based policy making beyond the fifteen countries and regions represented in the PACITA consortium. The events attracted participants from EU-28, Africa, Australia, South-America and Asia.

\section{Overview of the two summer schools}

The two summer schools' topics were centred on two 'grand challenges for Europe', particularly suitable to technology assessment approaches and methods. In Liège 2012, the topic was renewable energy systems, while in Cork 2012, the summer school there focused on ageing societies and new technologies. The complexity of these grand challenges and the great transitions that they necessitate appeared to be adequate backgrounds to call for new modes of interaction and exchange with and among 'new players' in technology assessment.

The first summer school ${ }^{1}$ was organized at the University of Liège, Belgium (25-28 June 2012). As a transnational concern and growing grand challenge for policy, economy and society worldwide, the topic of 'renewable energy systems' was chosen as an entry point for learning about TA. This challenge refers to the interplay of actors, technologies, policies, worldviews and institutions engaged in the field of energy debates, policies and production. Technologies play an important role in coping with such issues. At the same time, technologies can also be part of the problem. Participants at 
the summer schools were taught balanced, encompassing approaches and relevant TA methods to address the most pressing energy issues.

The second summer school was organized at the University College Cork, Ireland (17-20 June 2014). The topic chosen was 'challenges and opportunities of the ageing society: exploring the role of technology'. The event consisted of training sessions, practical exercises, mutual reflection, and networking. Figuring out how to cope with ageing societies is one of the grand challenges pointed out in the Lund Declaration, and health-care technologies can be increasingly important for society to offer health and care services at a quantity and quality that mirrors the expectations of the European population. The summer school participants debated how best we can use new technology in care services and what type of policy options policy makers are faced with.

\section{Summer school format}

Summer schools were a combination of lectures and interactive workshops. Lectures combined elements of the different phases of a TA project (problem definition and research design, methodology, communication and impact) with concrete examples or applications to the issue at stake. After each lecture, during the workshops the participants would have the chance to relate what they had learned in hands-on, problem-driven simulation and role-play exercises. The workshops' objective was to produce a coherent draft for a TA project. A facilitator helped participants with a 'script' that included minimal contextual information (such as the context in which a TA project was needed or the explicit demand from a politician's commissioning a study) and suggestions for sub-tasks (identifying the needed knowledge base, mapping relevant stakeholders, listing technological options, scrutinizing social issues as well as more practical tasks such as project management and communication).

Participants were split into two groups, and they were assigned different roles within the workshops, as happens in real TA institutions (e.g. researchers, project managers and communication officers). Before they started working, each group was given different variables such as the addresses of the project, the framing of the issue, the available budget, the timeframe for decisions to be made, the technologies involved, the existing expertise, the mapping of stakeholders or the socio-political context. Both groups were also given different assignments. This could for instance 
be a study that originated from a member of European Parliament's demand or from setting up a new project on a city level to then present it to TA's addressees. This resulted in the two groups presenting contrasting approaches, project management's choices and expected results. To finalize the training, the groups presented their work to each other in order to exemplify the diversity of possible TA approaches on a complex issue.

\section{Main results}

The summer schools can be considered as a first step in the construction and consolidation of an international TA community extended beyond the TA practitioners themselves. Numerous participants have kept in touch and established collaborations. Furthermore, once participants were introduced to the concept of technology assessment, they also attended other events in the TA community and particularly within the PACITA project, such as the Prague Conference or the practitioners training activities. In addition, the TA simulation exercises facilitated a common understanding and shared interest in TA, thus indirectly strengthening the support base for establishing TA in other European countries. Summer schools also confronted TA practitioners with various ontologies of technology assessment.

Lastly, for participants and TA practitioners alike, summer schools provided a platform for mutual learning, not only about technology and grand challenges but also about the views of various societal actors on TA. This continuous iterative learning approach is especially relevant in the context of expanding the TA landscape, as it helps provide the traditional TA players with a feedback mechanism from the new players who are sensitized to what TA is and what it can deliver.

\section{Future agenda for TA education in the context of 'responsible innovation'}

Today, with the discourse of addressing grand challenges (especially in the European Union; cf. Lund Declaration or Horizon 2020), the promises of and strategies for technology are not yet very specific. At the same time, it has become widely acknowledged that governing grand challenges is a complex issue that requires knowledge-based policy-making solutions. 
These evolutions call for recognition of the importance of governance, the broadening of government and the inclusion of more actors in collective choices that involve science and technology. Governance is actually distributed between a number of actors, which some definitions acknowledge: governance can be discussed as the coordination and control of autonomous but interdependent actors either by an external authority or by internal mechanisms of self-regulation or self-control (Mayntz and Scharpf, 1995, Benz, 2007), including de facto governance arrangements that emerge and become forceful when institutionalized (Kooiman, 2003). With such a notion of governance, it becomes understandable how the trend of grand challenges impinges on the governance of science, technology and innovation and how anticipating future developments and relating them to policy making has become a crucially important task for technology assessment.

In a first attempt at discussing the anticipatory governance of science and technology, Barben et al. characterized anticipatory governance as evoking a distributed capacity for learning and interaction stimulated into present action by reflection on imagined present and future sociotechnical outcomes (Barben et al., 2008: 993). On these grounds, summer schools can be taken as practical instances of anticipatory governance because they emphasized broadening the community of TA users and enhancing a distributed capacity to frame cutting-edge issues in terms coherent with TA frameworks and tools. An important lesson learned has been that TA knowledge is not produced by one actor in isolation before it is transferred to other actors deemed to use the subsequent insights. Rather, TA knowledge is co-produced by a range of actors who contribute in order to collectively generate knowledge resources, partly already informed by governance issues.

Recently, there has been increasing attention to that idea in connection with policy discourse on the concept of Responsible Research and Innovation (RRI). One influential definition of this concept combines good intentions with anticipation and mates it with attempts at anticipatory governance (Owen, Bessant and Heintz, 2013). In this definition responsibility has a prospective element (it is more than accountability) and 'responsible development' is a multi-actor distributed process. Therefore this type of governance qualifies as anticipatory governance. There are bottom-up dynamics, but at the moment, the policy discourse is most visible. More should be done in order for the policy discourse to be more firmly and systematically entrenched in bottom-up innovative 
practices. Training new practitioners and potential users of TA, like it was done in the summer schools, adds a practical dimension to the debate and contributes to the European strive for ensuring societally responsible research and innovation.

\section{Note}

1 See also the article by Pascale Messer in the VolTA magazine: http://volta. pacitaproject.eu/pacita-summer-school-2012/.

(C) (1) Except where otherwise noted, this work is licensed under a Creative Commons Attribution 4.0 Unported License. To view a copy of this license, visit https://creativecommons.org/version4 